\title{
Apontamentos sobre o crescimento do Carnaval de rua no Rio de Janeiro no início do século 21
}

\author{
Micael Herschmann*
}

\begin{abstract}
Resumo
Tomando como base a pesquisa empírica realizada entre 2012 e 2013 (construída a partir da coleta, seleção e análise de matérias veiculadas na mídia impressa tradicional e material postado nas redes sociais, de observações de campo e entrevistas semiestruturadas realizadas com os atores sociais), busca-se avaliar em que medida o crescimento do Carnaval de rua na cidade do Rio de Janeiro, desde meados da primeira década do século 21, está em alguma medida relacionado (mas não de forma exclusiva) a um ativismo musical realizado nos espaços públicos desta localidade. A hipótese que norteia os argumentos aqui desenvolvidos é a de que há um consistente movimento musical de rua - que envolve não só redes de músicos amadores, semiamadores (e até profissionais), mas também produtores e fãs, os quais atuam em neofanfarras e rodas (de samba, choro e jazz) - que vem contribuindo de forma significativa para o crescimento expressivo do Carnaval de rua carioca nos últimos anos.
\end{abstract}

Palavras chave: Comunicação. Cultura Urbana. Música. Carnaval. Rio de Janeiro.

\section{Notes on the growth of street Carnival in the Rio de Janeiro at the beginning of the $2 I^{\text {th }}$ century \\ Abstract}

Based on the empirical research conducted between 2012 and 2013 (built from the collection, selection and analysis of articles published in traditional print media and material posted on social networks, field observations and semi-structured interviews with social actors), in this article search to evaluate to what extent the growth of street Carnival in the city of Rio de Janeiro, since the mid-first decade of this century, is to some extent related (but not exclusively) to

* Professor doutor do Programa de Pós-Graduação em Comunicação e profes sor associado do Departamento de Fundamentos da Comunicação, da Escola de Comunicações (ECO), da Universidade Federal do Rio de Janeiro, Rio de Janeiro-RJ, Brasil. E-mail: micaelmh@pq.cnpq.br 
a musical activism conducted in public this locality. The hypothesis that guides the arguments developed here is that there is a consistent musical movement street - which involves not only networks of amateur musicians, semi amateur (and even professional), but also producers and fans, which act in brass-bands and rodas (of samba, choro and jazz) - which has contributed significantly to the significant growth of the street Carnival in Rio in recent years.

Keywords: Communication. Urban Culture. Music. Carnival. Rio de Janeiro.

\section{Notas sobre el crecimiento del Carnaval de calle en Rio de Janeiro en los principios del siglo 21 \\ Resumen}

Tomando como referencia la investigación empírica llevada a cabo entre 2012 y 2013 (que se ha constituido con base en relevamientos, selección y análisis de los artículos publicados en los medios impresos tradicionales y el material publicado en las redes sociales, observaciones de campo y entrevistas semi estructuradas con actores sociales), búsqueda para evaluar en qué medida el crecimiento del Carnaval de calle en la ciudad de Rio de Janeiro, desde mediados de la primera década de este siglo, es en cierto modo relacionada (pero no exclusivamente) a un activismo musical realizado en público esta localidad. La hipótesis que guía a los argumentos desarrollados aquí es que hay un constante movimiento musical calle - lo que implica no sólo a las redes de músicos amateurs, semi amateurs (e incluso profesional), sino también a los productores y aficionados, que actúan en neofanfarras y rodas (de samba, choro y el jazz) - que ha contribuido de manera significativa al crecimiento significativo de la calle del Carnaval en Río de Janeiro en los últimos años.

Palabras clave: Comunicación. Cultura Urbana. Música. Carnaval. Rio de Janeiro.

\section{Introdução}

[Atualmente há um] [...] sentimento de vitória com a retomada do carnaval de rua do Rio de Janeiro, depois de seguidos anos de pouca atividade [...]. O que afastou os foliões? O que isolou as escolas na Marquês de Sapucaí? Por que os Blocos foram minguando? O que aconteceu com os ranchos, as marchinhas, os bailes nos coretos e com o próprio samba especialmente nas décadas de 70 e 80? [...] Aparentemente, não existem opiniões consolidadas sobre esse tema. [...] A ditadura fez recair sobre o país um clima de tristeza e obscurantismo. Reuniões de jovens e populares eram sempre mal vistas pela repressão e o Rio de Janeiro foi um dos locais de maior luta e resistência à ditadura. Ao mesmo tempo, o samba perdeu lugar para o rock e foi sumindo das programações de rádio e TV a partir da década de 80.[...] Podemos apontar também como fatores que influenciaram esse declínio, o crescimento desordenado da cidade, a transferência de comunidades ca- 
rentes da Zona Sul para a Zona Oeste, a escalada da violência urbana [...]. As escolas de samba, antes dirigidas por sambistas e gente da comunidade, passaram a serem administradas pelo jogo do bicho, celebridades e empresários [...]. As grandes gravadoras não abriam espaço para o samba. Um ou outro artista ocupava o restrito espaço de mídia destinado ao gênero. [...] Ao mesmo tempo crescia o carnaval de rua em outras cidades como Recife e Salvador [...] e com isso o Rio perdia mais espaço no cenário nacional (MARQUES, 2006, p.2-3).

Ao longo da pesquisa realizada ${ }^{1}$ pode-se constatar que a festa do Carnaval até o final dos anos de 1990, em certo sentido encontrava-se de certo modo "esvaziada" (tinha sido "domesticada" nos seus aspectos mais dionisíacos ${ }^{3}$ ), isto é, à exceção de alguns blocos mais tradicionais que continuavam realizando seus cortejos $^{4}$, o Carnaval carioca chegou ao final do século 20 como uma celebração circunscrita ao desfile da escola de samba do sambódromo e a um punhado de bailes realizados em clubes.

Atualmente, o Rio de Janeiro vive uma espécie de explosão do seu Carnaval de rua, à semelhança das primeiras décadas do século passado, a cidade é invadida por agrupamentos de foliões organizados das mais variadas formas. Chamados indiscriminadamente de bandas ou blocos, esses grupos podem

\footnotetext{
${ }^{1}$ Optou-se por pesquisar mais diretamente alguns grupos musicais de rua que atuam como neofanfarras, rodas e blocos (tais como o Orquestra Voadora, Monte Alegre Hot Jazz Band e o Cinebloco) pelas seguintes motivações: a) a popularidade destes grupos; b) e/ou a identificação deles com o "renascimento do Carnaval de rua carioca" e com a cultura musical de rua da cidade. Tomou-se como importantes referências as pesquisas realizadas sobre o Carnaval carioca, por especialistas como VIANNA (1999), PRESTES FILHO (2010), CAVALCANTI (2006) e PIMENTEL (2002).

2 Ainda que na sua simbologia o desfile do Carnaval do Rio de Janeiro continuasse a ser exibido e comercializado como parte do "panteão nacional" e atraindo olhares de foliões, curiosos e turistas de várias partes do globo, do ponto de vista da participação popular (especialmente dos moradores da cidade do Rio) a festa dava fortes evidências de crise naquela época.

${ }^{3}$ Sobre o ritual do Carnaval e sua dimensão dionisíaca e irruptiva, ver: BAKTHIN, 2010; MATTA, 1997.

${ }^{4}$ Alguns blocos da Zona Norte, Santa Teresa e da Zona Sul seguiam atraindo o interesse de parcela significativa de público nesta celebração momesca, tais como Cordão do Bola Preta, Cacique de Ramos, Carmelitas, Bloco da Segunda, Banda de Ipanema, Simpatia Quase Amor e Suvaco do Cristo (BEI, 2007).
} 
desfilar cantando um único samba composto especialmente a cada ano, ao som de marchinhas carnavalescas tradicionais ou de ritmos variados como maracatu, ciranda ou rock. O acompanhamento musical pode ser uma bateria, ao estilo das escolas de samba, uma bandinha "furiosa" ou uma mistura de vários instrumentos (BEI, 2007, p.7).

Entretanto, no início do século 21, o Carnaval carioca impulsionado pela iniciativa espontânea dos atores sociais volta a ganhar força através dos blocos (e grupos musicais) que tomam as ruas da cidade. Para muitos dos seus frequentadores e especialistas, este boom do Carnaval de rua carioca representa a retomada da tradição do Carnaval do século 19 e 20, isto é, uma retomada da festa espontânea dos entrudos, ranchos, cordões e das sociedades carnavalescas (BEI, 2007; MARQUES, 2006). Sem entrar no mérito do debate sobre a tradição do Carnaval local, é possível constatar algumas diferenças neste novo contexto do Carnaval e que dizem respeito à expansão da temporalidade desta celebração e ao número de atores sociais envolvidos, especialmente de classe média. Para que se tenha uma ideia da importância dos blocos de rua no Rio de Janeiro: a celebração destes cortejos passaram a ocupar os meses de verão - foram convertidas em importantes atividades de entretenimento de veraneio - e, como consequência, ampliou-se oficiosamente a festa de Carnaval de uma semana para praticamente dois meses.

Crescentemente mais sensíveis aos benefícios que são gerados pela atuação dos blocos, o poder público tem procurado apoiar, normatizar e explorar o Carnaval de rua com o objetivo de atrair visitantes e recursos ao Rio de Janeiro. É comum encontrar matérias publicitárias nomeando o Carnaval do Rio como o "maior do mundo", em função especialmente da escala de ocupação dos espaços públicos pelos blocos. Segundo estudo realizado por Prestes Filho, o Carnaval do Rio de Janeiro vem movimentando uma economia (da cultura) superior a $\mathrm{R} \$ 700$ milhões e gerando 500 mil empregos, diretos e indiretos (PRESTES FILHO, 2010). Na última década, a prática do Carnaval de rua na cidade do Rio não para de crescer, mobilizando moradores e turistas. Segundo também dados divulgados pelos órgãos oficiais de turismo e da 
Prefeitura do Rio, só no último ano o crescimento dos blocos na cidade foi de $10 \%$. Ainda tendo em vista as projeções da entidade: em 2012, aproximadamente 5,3 milhões de foliões desfilaram nos mais de 500 blocos pelas ruas do Rio durante o período de 13 a 26 de fevereiro (cálculo realizado levando em conta somente os blocos autorizados pelo poder público). Segundo o presidente da RIOTUR, Antônio Pedro Figueira de Mello, a região do Centro da cidade (e áreas da Zona Sul) é tradicionalmente a que concentra o maior público que acompanha os cortejos dos blocos 5 . Mello e outras autoridades do setor de turismo cada vez mais reconhecem que o Carnaval de rua tem colaborado de forma significativa para o crescimento desta cadeia produtiva nos primeiros meses do ano ${ }^{6}$.

O poder público e a galera que gosta de música na rua só consegue ver o produto final, que é esse mega carnaval de quase dois meses que a gente tem aí hoje, no Rio de Janeiro, que é um carnaval diferenciado, com blocos temáticos, blocos tradicionais, blocos de músicos conhecidos, e blocos das neofanfarras. Enfim, há no carnaval do Rio uma variação de propostas muito interessantes. Infelizmente, para o poder público, tudo é bloco. Tudo que está na rua é bloco, infelizmente não percebe certos detalhes. Temos um carnaval que dá muito dinheiro, que dá muito dinheiro para todo mundo, mas quase não chega recursos para os grupos de rua. Os músicos tocam

${ }^{5}$ Em 2012, os maiores públicos foram registrados nos seguintes blocos: Cordão da Bola Preta (2,2 milhões), Monobloco (500 mil), Afroreggae (400 mil), Bloco da Preta (250 mil) e o Cordão do Boitatá (200 mil pessoas) e todos desfilam no Centro. Mais informações conferir: VIANNA, Rodrigo. Blocos de rua atraem mais de 5,3 milhões de foliões, G1, 27/02/2012 (disponível em: <http://g1.globo. com/rio-de-janeiro/carnaval/2012/noticia/2012/02/blocos-de-rua-do-rio-atraem-mais-de-53-milhoes-de-folioes-diz-secretario.html>, último acesso: 30 de maio de 2012); VIANNA, Rodrigo. Confira a agenda pré-carnavalesca de blocos de rua do Rio, G1, 11/01/2012 (disponível em: http://g1.globo.com/rio-de-janeiro/ carnaval/2012/noticia/2012/01/confira-agenda-pre-carnavalesca-de-blocos-de-rua-do-rio.html >. Acesso em: 30 de maio de 2012).

${ }^{6}$ Mais informações conferir: VIANNA, Rodrigo. Blocos de rua atraem mais de 5,3 milhões de foliões, G1, 27/02/2012 (disponível em: http://g1.globo.com/ rio-de-janeiro/carnaval/2012/noticia/2012/02/blocos-de-rua-do-rio-atraem-mais-de-53-milhoes-de-folioes-diz-secretario.html. Acesso em: 30 de maio de 2012); VIANNA, Rodrigo. Confira a agenda pré-carnavalesca de blocos de rua do Rio, G1, 11/01/2012 (disponível em: http://g1.globo.com/rio-de-ais janeiro/ carnaval/2012/noticia/2012/01/confira-agenda-pre-carnavalesca-de-blocos-de-rua-do-rio.html>. Acesso em: 30 de maio de 2012). 
no carnaval, o dia todo, pra ganhar de 100 reais a 200 reais, enquanto a prefeitura e os empresários estão enchendo os cofres. [...] A verdade é que organizar um bloco é se meter numa grande enrascada! Quando um bloco consegue receber algum apoio é uma merreca, que varia entre cinco e dez mil reais. E, ai, depois do desfile, tem que pagar uma série de despesas, mas faltam recursos. Tem que pagar carros de som, um monte de músicos e o serviço de segurança. Mas paga mal, uma merreca para todo mundo. E algumas pessoas acham que estes blocos de rua deveriam pagar mais de um milhão de reais, em direitos autorais ao $\operatorname{ECAD~}[\ldots]^{7}$.

Neste artigo, parte-se do pressuposto de que o crescimento do Carnaval de rua na cidade do Rio de Janeiro desde meados da primeira década do século 21 está em alguma medida relacionado (mas não de forma exclusiva) a um ativismo musical realizado nos espaços públicos desta localidade por algumas redes de "prosumidores" . Em outras palavras, a hipótese que norteia este artigo é a de que há um movimento de música de rua que envolve grupos de músicos amadores, semiamadores (e até profissionais) - que atuam não só em rodas de samba, choro e jazz (jamsessions), mas também na forma de neofanfarras na cidade do Rio de Janeiro - que vem contribuindo para o crescimento do Carnaval de rua.

Objetiva-se assim com este trabalho repensar a importância da música de rua para a recuperação (especialmente) do Centro (histórico) da cidade do Rio. Ou melhor, busca-se avaliar a relevância da atuação destes grupos musicais pesquisados no processo de ressignificação da cidade, isto é, procura-se - a partir do estudo de caso do crescimento do Carnaval de rua carioca - fazer um balanço da competência desses atores em construir em territórios criativos capazes de alavancar em alguma medida o Desenvolvimento Local Sustentável desta urbe.

\footnotetext{
${ }^{7}$ Entrevista realizada com Miguel Maron, músico dos Siderais, no dia 05 de junho de 2013.

${ }^{8}$ Sobre o conceito de prosumidores e consumidores produtivos ver Canclini et al., 2012; Jenkins, 2010. Estes autores postulam que já há alguns anos vem se fragilizando as fronteiras entre o polo da produção e consumo (que sugerem uma dinâmica interativa e colaborativa, na qual é cada vez mais difícil separar o produtor do consumidor).
} 
Assim, a partir de uma extensa pesquisa de campo que vem sendo realizada de forma sistemática desde $2012^{9}$ - que envolveu a coleta, seleção e análise de matérias veiculadas na mídia impressa tradicional e material postado nas redes sociais, de observações de campo e entrevistas semiestruturadas realizadas com os atores sociais (produtores, músicos e fãs/consumidores) - postula-se que, como alguns destes coletivos atuam também como blocos de Carnaval de rua (vários bastante populares), há uma dificuldade em perceber que este ativismo musical de rua está alicerçando e impulsionando o crescimento desta importantíssima festa da cidade. Isto é, há uma "cultura musical de rua no Rio de Janeiro"10 atualizada pelas rodas, jamsessions e neofanfarras (HERSCHMANN; FERNANDES, 2011): “(...) apesar das condições adversas, o carioca gosta muito de estar na rua (...) pode-se dizer que a cultura de rua do Rio de Janeiro é diferenciada, talvez única no Brasil"11. Em outras palavras, há um processo de internalização de práticas, rotinas e habitus (BOURDIEU, 1991) que, apesar de não ter sido de modo geral constatado (e devidamente avaliado) pelo poder público e pela maioria dos especialistas do meio acadêmico, vem gerando resultados bastante significativos (benefícios socioculturais, econômicos e políticos diretos e indiretos), dos quais o estrondoso

\footnotetext{
${ }^{9}$ Este artigo traz alguns dos resultados preliminares do projeto de pesquisa intitulado "Comunicação, Música e Espacialidade". Agradeço, portanto, ao CNPq pelo apoio a esta investigação, a Cíntia Sanmartin Fernandes pelas contribuições e intercâmbio realizados durante a confecção deste artigo e, finalmente, as minhas incansáveis auxiliares de pesquisa de iniciação científica - Jaqueline Neves da Silva, Diana Ferraz e Juliana Araújo - pela colaboração no levantamento de inúmeras informações que foram importantes para a construção de inúmeros argumentos aqui expressos.

${ }^{10}$ Neste sentido, Leonardo Campos, do Orquestra Voadora, faz o seguinte comentário: "Acho que um dos diferenciais do ambiente cultural do Rio é que muita coisa rola na rua mesmo. Tocar na rua nesta cidade é muito bacana (...) acho que o carioca procura muito isso, a galera quer cultura e programa na rua" (entrevista realizada com Leonardo Campos, trombonista da Orquestra Voadora, em 08 de março de 2013).

${ }^{11}$ Entrevista realizada com Marco Serragrande, músico do Monte Alegre Hot Jazz Band, no dia 15 de janeiro de 2012.
} 
sucesso do Carnaval de rua carioca dos últimos anos é a mais forte evidência. Ou seja, esta evidência analisada aqui se constitui em uma espécie de parte visível deste gigantesco "iceberg", o qual coloca como desafio (aos pesquisadores) a necessidade de se repensar a expressiva "capacidade movente" da música no mundo contemporâneo ${ }^{12}$.

Portanto, vem se constatando na pesquisa em curso que esses artistas vêm mobilizando um público jovem significativo ao longo do ano, o qual vem se acostumando a apreciar a música de forma coletiva e na maior parte das vezes de maneira gratuita (e na rua). Esses atores conformam "redes" que gravitam em torno da música - constituem-se em agrupamentos de músicos e "prosumidores" (CANCLINI et al., 2012) que atuam também na Web (CASTELLS, 1999) - as quais vêm ocupando e reterritorializando a cidade, de forma expressiva, já há alguns anos.

\section{Da festa esvaziada a explosão da celebração nas ruas}

Como já foi assinalado anteriormente, apesar da cidade RJ ser um importante "celeiro de música" da produção musical do país (HERSCHMANN, 2010) e do Carnaval carioca ser uma festa emblemática, até o final dos anos de 1990 esta celebração parecia estar praticamente limitada ao desfile do sambódromo e a alguns bailes de clube, ou seja, constituía-se naquele momento em um evento bem mais restrito e, em grande medida, direcionado ao consumo do público externo.

A esta altura poder-se-ia indagar como este quadro foi alterado? Como foi que os atores locais se reapropriaram e ressignificaram mais uma vez esta importante festa da cidade? Poder-se-ia destacar dois momentos de retomada do Carnaval de rua no Rio, após o seu "esvaziamento" nos anos de 1970 e 1980:

a) há um primeiro momento de retomada do Carnaval de rua: quando ainda era um processo tímido, capitaneado

\footnotetext{
${ }^{12}$ Herschmann e Fernandes (2012a) sublinham a enorme capacidade mobilizadora da música na atualidade, especialmente quando as iniciativas que envolvem as sonoridades estão articuladas a indústria e lógica do entretenimento.
} 
por atores sociais de classe média e que começou a dar outro dinamismo ao Carnaval do Rio (até então praticamente restrito a semana da festa de Carnaval e aos blocos da Zona Norte que desfilavam no Centro ${ }^{13}$ ). À exceção da Banda de Ipanema (que atuava praticamente solitariamente desde 1965, na Zona Sul), os anos de 1990 é o momento em que aparecem grupos como Suvaco do Cristo, Simpatia Quase Amor, Bloco da Segunda, Bloco do Barbas, Escravos da Mauá, Clube do Samba e Carmelitas ${ }^{14 .}$

b) E, o segundo momento em que se inicia na primeira década do século 21, no qual há efetivamente um boom do Carnaval nas ruas do Rio: é possível atestar que há uma expansão temporal (o Carnaval se torna uma festa praticamente de veraneio) e espacial da festa (a sensação para muitos que não apreciam o Carnaval - especialmente o de rua - é que a cidade está quase "sitiada" pelos foliões) ${ }^{15}$. É importante destacar que este crescimento do Carnaval

13 Os desfiles do Bafo de Onça, Cacique de Ramos e do Cordão do Bola Preta no Centro eram considerados por vários atores como "bastiões da tradição mais autêntica do Carnaval" e seguiram atraindo expressivos segmentos sociais, mesmo no período da ditadura militar.

${ }^{14}$ A lenta retomada do Carnaval de rua nos de 1990 não é analisada em profundidade neste artigo, contudo é possível apontar algumas pistas. Marques sugere que o processo de redemocratização do país e uma reação por parte de lideranças do mundo do samba - insatisfeitas com o "engessamento da festa" (o tom oficial e vinculado quase que exclusivamente ao desfile das escolas de samba) e com apropriação do Carnaval por parte de grupos de empresários, políticos e de conglomerados de comunicação - contribuíram de forma decisiva para que surgisse um engajamento por parte de atores sociais de classe média e o processo de formação dos blocos de rua na Zona Sul do Rio de Janeiro (MARQUES, 2006). 15 Impressionada com o número de reclamações por parte dos moradores da cidade e alarmada com o crescimento dos blocos de rua da Zona Sul e, consequentemente, as dificuldades logísticas de alocá-los nos espaços públicos - "sem parar o cotidiano da cidade" - a Prefeitura da cidade não só vem negociando nos últimos anos a necessidade da transferência dos blocos para áreas do Centro (e até Aterro do Flamengo), mas também vem argumentando que irá reduzir o número de iniciativas que autorizará desfilar no Carnaval. Mais detalhes ver: DIAS, Marcelo. Eduardo Paes quer diminuir blocos na Zona Sul, Extra, Rio de Janeiro, 15/02/2013 (disponível em: http://extra.globo.com/noticias/rio/eduardo-paes-quer-diminuir-blocos-na-zona-sul-anuncia-licitacao-de-desfiles-das-escolas-de-samba-mas-sem-mickey-7588555.html>. Acesso: 11/07/2013.). 
de rua carioca continua ser resultado de um engajamento de foliões de classe média (inclusive nota-se que a média de idade dos envolvidos na festa vem caindo nas últimas décadas significativamente): a sensação que se tem ao assistir a festa é que esses cortejos de rua estão se convertendo, cada vez, mais em uma forma de entretenimento "juvenil"16. Poder-se-ia dividir em "duas ondas" este segundo momento de crescimento dos blocos. Uma, na primeira metade da década passada, em que claramente havia uma preocupação da juventude que frequentava o circuito da Lapa com a retomada e expansão da "tradição do samba de raiz" (HERSCHMANN, 2007): traçam-se parâmetros que vão nortear a criação de alguns blocos sempre citados como referências fundamentais, tais como Cordão do Boitatá, Boi Tolo e Céu na Terra (que tradicionalmente arrastam centenas de milhares de pessoas pelas ruas da cidade). E, a "segunda onda", que começou na segunda metade da década inicial do século 21 , que veio se somar ao movimento sociocultural existente, e que colocaram no epicentro os blocos temáticos, os blocos das fanfarras, os cortejos de rua que incorporam outros ritmos (e outros gêneros musicais atípicos do mundo do samba) e, ainda, os blocos que estão ligados à trajetória de músicos profissionais. Poder-se-ia mencionar como exemplos destes blocos os seguintes agrupamentos: Sargento Pimenta, Orquestra Voadora, Monobloco, Bloco da Preta, Cinebloco, Gigantes da Lira, Fogo Eु Paixão e Super Mario Bloco, entre vários outros.

Ainda que seja difícil precisar exatamente o que levou ao boom dos cortejos dos blocos de rua, poder-se-ia listar ainda alguns dos fatores que contribuíram para o reagenciamento da festa pelos atores no início do século 21:

\footnotetext{
${ }^{16}$ A noção de jovem e juventude é considerada aqui um construto sociocultural (MARGULIS, 1996; LEVI e SCHMIDT, 1996; BORRELLI, 2008). Entretanto, neste artigo está se fazendo especificamente referência a queda da faixa etária dos foliões que participam dos blocos de rua no Rio.
} 
a) Em meados dos anos de 1990 inicia-se o ciclo virtuoso da Lapa: pode-se afirmar que se assiste há quase duas décadas ao crescente sucesso desta microrregião, em grande medida dedicada a produção e consumo de "música de raiz" - que entronizou um circuito de samba e choro na localidade (HERSCHMANN, 2007) - e onde havia casas de espetáculo (bastante populares) nas quais artistas apresentavam performances que invariavelmente promoviam fusões do samba com outros gêneros musicais. Assim, novas gerações de moradores da cidade do Rio e frequentadores da área começaram a se interessar mais pelo mundo do samba: vai se fortalecendo um conjunto de habitus (BOURDIEU, 1991), de rotinas de consumo que gravitam em torno deste gênero musical.

b) Surgimento de blocos com o "perfil mais jovem e renovado" - tais como Monobloco, Bloco da Preta, Vagalume e Bagalafumenga. Emergem também blocos com um repertório musical que mescla o samba e as marchinhas tradicionais com propostas "arrojadas" (tocando até trilha de filmes e de videogames) e/ou outros ritmos e gêneros musicais. Assim, apesar da resistência dos segmentos mais conservadores, nos últimos anos, cresce a importância de blocos como, por exemplo, o do Sargento Pimenta, Orquestra Voadora, Fogo $\mathcal{E}$ Paixão e Super Mario Bloco com um repertório mais diversificado e mais identificado com os foliões de menor faixa etária.

c) Vários atores que já tocavam na rua e de forma exitosa em grupos musicais tais como, por exemplo, os que atuam no Monte Alegre Jazz Hot Band, Siderais, Cinebloco e Orquestra Voadora (entre outros) passaram, de forma sistemática, a considerar cada vez mais a participação nos blocos uma espécie de extensão do conjunto de atividades que em geral um músico realiza no Rio de Janeiro. Aliás, levando em conta os depoimentos concedidos por vários músicos à pesquisa, pode-se notar que eles consideram este um momento importante, não 
só pela possibilidade de intensa fruição (pelos aspectos dionisíacos), mas também pela chance de tocar para um público maior (para além do habitual que frequentava as rodas, jamsessions e neofanfarras) ${ }^{17}$.

d) Diante da crise da indústria da música, há uma mudança na postura dos músicos (amadores, semiamadores ou mesmo profissionais): muitos músicos resolvem radicalizar a experiência indie da musica, superar o constante "lamento" com o processo de reestruturação da indústria da música (crise do modelo do século 20, baseado no fonograma) $)^{18}$ e procuram "reinventar-se" não através das gravadoras independentes (também muito desorientadas neste processo), mas sim a partir do principio do prazer de tocar e interagir nas redes sociais. Muitos deles disponibilizam seus conteúdos (não se importam com a troca livre de fonogramas) e percebem que precisam construir laços com os consumidores. Assim, o ativismo musical emergiria como uma maneira desses atores adquirirem

\footnotetext{
${ }^{17}$ Ainda necessita ser mais bem investigada esta hipótese, mas provavelmente o fato desta cidade concentrar boa parte dos músicos do país e a competição por visibilidade e espaço no mercado ser mais intensa no Rio, pode ter induzido muitos artistas a identificar nos desfiles dos blocos uma oportunidade de se "realizar como músico" (ainda que de forma episódica e pontual).

${ }^{18}$ Passado um momento de maior perplexidade dos profissionais da indústria da música, é possível afirmar que este setor da produção cultural está se reestruturando. Analisando os últimos dados divulgados pelos institutos e associações de música nacionais, é possível constatar que novos negócios e hábitos de consumo estão se consolidando no mundo, ainda que estes não sejam "visíveis" (pelos níveis de informalidade e pela falta de interesse em gerar certo tipo de indicadores culturais do setor da música) e/ou que os seus benefícios diretos e indiretos destas iniciativas não se reflitam em uma recuperação mais efetiva da chamada grande indústria da música. Esses business, que não são exatamente "novos", apesar de alguns serem inovadores (do ponto de vista tecnológico ou do tipo de relação que se estabelece com os usuários-consumidores), estão associados às apresentações musicais "ao vivo" - shows avulsos, circuitos, cenas e festivais independentes - e às novas estratégias de comercialização de fonogramas (grande parte das vendas está articulada às estratégias desenvolvidas pelas empresas junto às plataformas multimídia de games, aos aparelhos celulares e aos sites da internet) (HERSCHMANN, 2010).
} 
algum "capital simbólico" (BOURDIEU, 1983) junto aos fãs. É necessário salientar que a velha indústria da música desmantelou-se no final do século 20 e o público hoje: por um lado, está pouco disposto a pagar pelos fonogramas; e, por outro lado, valoriza muito os concertos ao vivo e, eventualmente, pode vir a pagar pelos mesmos ou pelos souvenires desta experiência sonora coletiva (tais como camisetas, bottons e até CDs e DVDs). O que se nota é que para a grande maioria dos músicos (especialmente os que estão fora do chamado mainstream) é que a ideia de uma "carreira" linear (e que pode ser galgada em etapas) tende a entrar em crise e cada vez mais eles abraçam a ideia de "projeto" (CANCLINI et al., 2012) que pode não resolver o desafio da sustentabilidade, mas sem dúvida vem permitindo que alguns deles alcancem níveis de realização. Com isso também as noções e as fronteiras entre o amadorismo e profissionalismo musical tendem a se borrar, pois os parâmetros para classificar essas trajetórias de vida já não são tão claros. Aliás, vários artistas profissionais com carreiras já consolidadas e que de certa maneira fazem parte do mainstream musical (tais como Pedro Luis, Rodrigo Maranhão e Preta Gil) - buscam na organização e participação em blocos de Carnaval do Rio o desenvolvimento de um conjunto de estratégias que tem como meta a expansão da sua rede de fãs.

e) Houve também um processo de retroalimentação: ou seja, o próprio Carnaval de rua (e os desfiles de Carnaval) do passado, enquanto uma tradição que "deveria ser resgatada", também foi uma fonte de inspiração não só para o boom dos cortejos momescos nos espaços públicos, mas também para a realização das rodas e das fanfarras que mantém viva e atualizada a cultura musical de rua do Rio. Na pesquisa realizada com os atores, identificou-se um número expressivo de discursos que acionam narrativas que, em certo sentido, "reinventam 
esta tradição" (HOBSBAWN; RANGER, 1984), isto é, um grande número de enunciados vem sendo acionado para justificar a ocupação mais intensa das ruas, especialmente no início do século 21.

f) Na última década, constata-se também que a ampliação da sensação de segurança nas ruas da cidade vem motivando os jovens e, de modo geral, os atores sociais, a ocupar os espaços públicos. Poder-se-ia afirmar que vem se construindo um "imaginário" (LEGROS et al., 2007) de uma cidade do Rio de Janeiro "pacificada" (ABROMAVAY; GARCIA CASTRO, 2011) ${ }^{19}$.

g) O emprego das redes sociais da Web para mobilizar os fãs, frequentadores e músicos combinado a uma ampliação do espaço oferecido pela mídia tradicional para divulgação dos blocos de rua contribuíram significativamente. Poder-se-ia afirmar que ambos foram fundamentais para dar mais visibilidade, prestígio e destaque a retomada do Carnaval de rua.

Evidentemente, é possível ainda relacionar outros fatores que contribuíram em algum nível para o boom, sem precedentes, do Carnaval de rua carioca. Aliás, Rita Fernandes, presidente da Sebastiana (Associação Independente dos Blocos da Zona Sul, Centro e Santa Teresa), além de reiterar algumas hipóteses sugeridas aqui, acrescenta outras menos prováveis: a) o aumento da autoestima do carioca (que parece mais uma consequência do que causa desta "retomada dos cortejos de rua"); b) e postula - contradizendo de certo modo os dados divulgados pelo IBGE referentes à década passada - que houve uma perda de poder aquisitivo da chamada classe média:

\footnotetext{
${ }^{19}$ Inúmeras iniciativas de grande repercussão social - não só como o programa de implantação das UPPs, mas também campanhas publicitárias que atualizam a ideia da Cidade Maravilhosa promovidas por empresários e pelo poder público da região, bem como a intensa veiculação de enunciados jornalísticos que valorizam o Rio (embalados em grande medida pelo noticiário dos eventos esportivos e de entretenimento que vem sendo realizados nesta localidade) - vêm construindo uma imagem mais positiva da cidade, que seria supostamente mais próspera e segura (ABROMAVAY; GARCIA CASTRO, 2011).
} 
A retomada do carnaval de rua foi um processo [...] foi ganhando corpo aos poucos e por diversas razões. Paralelamente ao surgimento dos blocos, houve um resgate do samba e do choro, que distintos, mas casados, tem origem na mesma raiz: a autoestima do carioca, que andava por baixo por conta da violência. [...] os mesmos grupos que fizeram renascer essas rodas de samba e de choro são os que fizeram ressurgir o carnaval de rua do Rio. Os núcleos dessas rodas e dos blocos, os sambistas, os músicos, e os frequentadores, eram os mesmos. Outra razão para o carnaval de rua voltar a ganhar corpo foi o empobrecimento da classe média carioca. Ela foi perdendo poder aquisitivo e foi deixando de viajar no carnaval como fazia antes [...], assim teve que reinventar seu carnaval aqui mesmo, investindo em uma festa da cidade que estava relegada somente ao Sambódromo. E para completar, a própria mídia redescobre esse carnaval, a partir de 2000, e faz explodir o movimento, atraindo muitos turistas [...] (apud PRESTES FILHO, 2010, p.250).

\section{Pesquisando a cultura musical de rua carioca que atua no Centro}

Provavelmente se o escritor João do Rio estivesse vivo e em atividade: para explicar a cultura musical de rua presente na atualidade descreveria uma cidade do Rio de Janeiro "submersa", quase "invisível" e que emerge com toda intensidade no Carna$\mathrm{val}^{20}$. Ainda que isso só seja percebido claramente no Carnaval, esta urbe é ocupada (especialmente na área central) de forma capilar pelos atores que, assim, em diferentes localidades, tocam, cantam e dançam, ressignificando seu cotidiano e a relação com os espaços públicos da localidade ${ }^{21}$.

Parte-se do pressuposto de que há uma espécie de ativismo ainda meio invisível e pouco compreendido pelos produtores musicais e pela crítica. Um dos produtores mais ativos da cidade, Thiago Vedová, afirma em uma entrevista realizada “(...) que o carioca está mal acostumado a não pagar pelos shows, habituou-se

\footnotetext{
${ }^{20}$ É esta a sensação que o leitor tem ao ler ao alguns livros de João do Rio como, por exemplo: Religiões no Rio(2006) e Alma encantadora das ruas (2008) - sobre esta cidade no início do século 20.

${ }^{21}$ Evidentemente, não confundir este comentário com o velho e surrado estereótipo do carioca, construído ao longo do século 20 e que tomava como referência algumas obras do chamado samba exaltação, figuras como Zé Carioca (personagem criado pelos Estúdios Disney) e/ou as performances musicais de Carmen Miranda.
} 
ao excesso de música gratuita oferecida na rua" (HERSCHMANN; FERNANDES, 2012b, p.7).

Talvez para um olhar mais "atento" ao novo "negócio da música” (que vem emergindo no século 21) considere este "ativismo musical de rua" - o qual esta expresso na vitalidade das rodas, jamsessions e neofanfarras que estão sendo criadas nos últimos anos na cidade 22 - como uma inovação relevante. Ainda que não resolva o desafio da sustentabilidade no setor da música, estas iniciativas podem estar sinalizando um "caminho alternativo" para que alguns jovens possam encontrar mais satisfação e realização na produção e consumo musical atual. Nota-se, neste conjunto de rotinas e práticas que gravitam em torno do espaço público, que não só os atores podem alternar a oferta de conteúdos de forma gratuita ou remunerada, mas também que eles têm encontrado maneiras de financiar a oferta de música grátis na rua de forma continua. Além disso, com frequência, nas entrevistas realizadas com os atores emerge: por um lado, menos uma preocupação com a "carreira" e com certos produtos que dão status aos músicos, tais como CDs e DVDs; e, por outro, mais uma constante preocupação com a inclusão, integração e ampliação das suas redes de fãs ${ }^{23}$.

\footnotetext{
${ }^{22}$ Vem se pesquisando a cultura musical de rua do Rio, isto é, vem se realizando um extenso e detalhado trabalho de campo - inspirado na "teoria do ator rede (ANT)" (Latour, 2008) - especialmente junto aos seguintes agrupamentos (que incluem não só as fanfarras mencionadas): Jazz na Pedra do Sal, Siderais, Cinebloco, Samba da Ouvidor, Roda de Choro Antigamente, Roda da Pedra do Sal, Monte Alegre Jazz Hot Bande Orquestra Voadora.

${ }^{23}$ Este depoimento de Pedro Araújo é bastante elucidativo da postura adotada por alguns grupos musicais de rua do Rio em relação aos seus fãs: “(...) Até tocamos em casas de espetáculo, mas é na rua que a gente rende mais. [...] Temos algumas músicas autorais, mas a gente não se vê como uma banda qualquer, que só visa o sucesso e um contrato com uma boa gravadora. [...] Claro que a gente fica feliz de poder gravar um CD.[...] Tudo isso é bacana, mas não é o mais importante. Nós que trabalhamos no Orquestra Voadora estamos preocupados em como nos integrar mais com a galera que acompanha nossos shows. Queremos inclui-los o máximo possível. [...] $\bigcirc$ financiamento do nosso trabalho é feito através de editais e leis de incentivo [...]" (entrevista realizada com Pedro Araújo, músico do Orquestra Voadora, no dia 08 de março de 2013).
} 
Em outras palavras, a música de rua vem sendo defendida pelos atores como uma prática "libertária" que pode tornar mais acessível a experiência musical aos músicos e consumidores (ao se posicionarem na rua, estes atores afirmam que diminuem a dependência em relação aos tradicionais "intermediários" - tais como gravadoras, empresários, produtores, empresas de comunicação etc. - para a realização dos concertos).

É interessante notar que a cultura musical de rua vem se ampliando especialmente no Centro do Rio de Janeiro. Parte-se do pressuposto de que a geografia e a arquitetura são vetores condicionantes e que vem contribuindo para a formação dessas "territorialidades sônico-musicais" (HERSCHMANN; FERNANDES, 2012b). Os atores que atuam nestas redes de músicos e fãs afirmam em seus depoimentos que as ruas do Centro por sua beleza e posicionamento geográfico facilitam e atraem o trânsito e o encontro entre os interessados e, assim, acabam se constituindo em uma espécie de "grande vitrine". Consequentemente, é possível constatar que estas redes de prosumidores vêm adquirindo cada vez mais visibilidade nas praças, jardins e "ruas-galerias" desta região. Reiterando argumentos desenvolvidos em trabalhos anteriores (HERSCHMANN; FERNANDES, 2012b): no seu conjunto, estes elementos articulados a música constroem uma "paisagem sonora" (SCHAFER,1969) capaz de mobilizar segmentos sociais significativos e que vem proporcionando uma série de benefícios diretos e indiretos aos atores locais e, de certo modo, às áreas das urbes em que atuam (HERSCHMANN, 2007, HERSCHMANN; FERNANDES, 2012b).

Nunca conseguimos apoio do pessoal do MAM, dos ambulantes locais ou da Prefeitura. Ocupamos aquele espaço, que antes da nossa chegada, era meio abandonado, meio sinistro. Era bonito, mas abandonado e cheio de moradores de rua. Então, fizemos tudo totalmente na base da autogestão, no peito e meio mambembe, pois nosso estilo é rueiro mesmo. Nunca teve um lugar que a gente não tivesse conseguido tocar, até porque a gente não precisa necessariamente amplificar os instrumentos. Agora a gente percebe que depois da nossa chegada o lugar ficou mais bem frequentado e isso beneficiou a todos $[\ldots]^{24}$.

${ }^{24}$ Entrevista realizada com Leonardo Campos, músico da Orquestra Voadora, em 08 de março de 2013. 
Como já mencionamos anteriormente, parte-se do pressuposto aqui que há uma correspondência entre os atores que promovem, ao longo do ano, a música de rua nesta cidade e os que organizam e participam de forma engajada no Carnaval de rua.

O Carnaval do Rio, é um grande momento, é uma vitrine dessas manifestações musicais de rua. E o Carnaval do Rio de Janeiro é diferente de todos os carnavais de rua do Brasil, no sentido de que ele vem sendo conduzido especialmente por jovens de classe média da cidade. [...] As pessoas que tocam nas fanfarras e blocos estão ali um pouco por conta do prazer de tocar para a galera e um pouco pela perspectiva de alavancar a sua atividade de músico. [...] Além dos blocos mais tradicionais, o pessoal das fanfarras ajudou a reinventar o carnaval de rua que mescla ritmos como, por exemplo, o pessoal da Orquestra voadora faz. Alguns grupos também inventaram blocos temáticos como a proposta do Super Mario Bloco, voltado para as músicas de games, ou o Cinebloco, com músicas de trilhas de filmes conhecidos $[\ldots]^{25}$.

Há algumas evidências de que este ativismo musical que vem tomando as ruas do Rio na última década é um fenômeno de classe média e que está concentrado na Zona Sul. Analisando o perfil dos prosumidores constatamos que, em sua grande maioria, são jovens estão numa faixa etária entre 16 e 30 anos. A grande maioria vive com os pais (estão na condição de "moratória social"²6) e, portanto, a pressão por garantir sua sustentabilidade é menor que a de outros jovens com menos recursos. Em outras palavras, possuem tempo e condição socioeconômica para se lançar nesta rede colaborativa, isto é, podem ainda se arriscar a não mercantilizar tanto seu trabalho e a relação com o público. Mesmo quando analisamos os 500 blocos que estão registrados na Prefeitura e que desfilam no Carnaval constata-se isso. Apenas um terço desses são oriundos e organizados por atores da Zona Norte, Centro (incluído o bairro

\footnotetext{
${ }^{25}$ Entrevista realizada com Miguel Maron, músico dos Siderais, no dia 05 de junho de 2013.

${ }^{26}$ Margulis (e outros autores) define a "moratória social" como um prazo concedido a certa classe de jovens, que lhes permite gozar de uma menor exigência enquanto completam sua instrução e alcançam sua maturidade social. Esta moratória permitiria prolongar a entrada na vida adulta e, consequentemente, a necessidade desses atores assumirem várias responsabilidades (MARGULIS, 1996).
} 
de Santa Teresa) e Zona Oeste. O fato de haver ainda pouco apoio por parte da Prefeitura para organização e realização dos blocos ${ }^{27}$ e das comunidades da Zona Norte e Oeste estarem praticamente engajadas de forma exclusiva na organização das escolas de samba (utilizam os parcos recursos disponíveis para este fim), explica em grande medida porque o Carnaval de rua é atualmente, em grande medida, um fenômeno sociocultural da juventude da classe média da Zona Sul. Fernandes, presidente da Sebastiana, dá algumas dicas para entender isso, lembrando que há uma "economia dos blocos de rua”, a qual envolve o pagamento de serviços que são essenciais para a organização e desfile dos blocos, especialmente os de médio e grande porte.

Muitas das baterias dos blocos de rua são pagas e podem envolver a presença de 50 a 80 componentes. [...] Além disso, há o serviço das costureiras para as camisetas. Cada bloco faz hoje milhares de camisetas. Há também os profissionais que fazem o silk nelas. [...] Isso sem falar das faixas, filipetas e a impressão de ventarolas e letras de samba. Há também o serviço de som [...]. Aliás, um bom carro de som exige um investimento alto [...]. Outro mercado que esta crescendo muito hoje é o das alegorias, fantasias, perucas e adereços (apud PRESTES FILHO, 2010, p.251).

\section{Considerações finais}

Tendo em vista o estudo de caso analisado, poder-se-ia afirmar que esses jovens destas redes pesquisadas são empreendedores - ainda que não tenham emprego formal no setor da música e não estão propriamente institucionalizados -, isto é, no mesmo sentido sugerido por Canclini (em uma extensa pesquisa recente realizada com agrupamentos juvenis do México e de Madri), eles atuam com frequência na qualidade de trendsetters (CANCLINI et al., 2012). Ou seja, muitas vezes sinalizam e promovem novas tendências significativas.

${ }^{27}$ Evidentemente, os blocos de rua são custeados da seguinte maneira: contribuição voluntária dos envolvidos, iniciativas de crowdfunding, editais de financiamento público ou a aplicação de leis de incentivo a cultura. 
Diferentemente do que se frequentemente imagina: se aplicadas políticas públicas inclusivas, de potenciais protagonistas que lançam "desafios sociais" estes jovens poderiam ser convertidos em agentes de inovação, os quais podem contribuir em algum nível para a "revitalização" de megacidades, como a do Rio. A verdade é que estes atores - mesmo que isso não seja percebido desta maneira - podem estar gerando importantes renovações e conduzindo processos tão desejados de recuperação e dinamização do espaço urbano.

Talvez possa se vislumbrar no horizonte um novo "negócio musical" (para além do mundo do indie e do mainstream), que já possui seus esquemas de financiamento organizados ${ }^{28}$.

Em outras palavras, na atuação desses coletivos - já que esses trazem claramente reflexos positivos que vão muito além destas redes socioculturais e subsidiam significativamente o incremento da cadeia produtiva da gastronomia, do entretenimento, e especialmente a do turismo (como no caso do Carnaval de rua do Rio) -, há espaços desta urbe que são claramente favorecidos por este tipo de ocupação. Em resumo, as "territorialidades sônico-musicais" (HERSCHMANN; FERNANDES, 2012a) que são elaboradas pelos atores geram inúmeros benefícios diretos e indiretos, revitalizando localidades importantes desta cidade (como os corredores culturais e centros históricos) que são selecionados por eles a partir de alguns critérios básicos ${ }^{29}$.

\footnotetext{
${ }^{28}$ Neste sentido, Leonardo Campos destaca que: "[...] usamos sites de financiamento coletivo e editais públicos, mas não passamos chapéu na rua, pois no Brasil isso não é bem visto. Na Europa, grandes músicos fazem isso, sem problemas, mas aqui o pessoal desvaloriza. [...] Buscamos recursos através de apoio oficial ou do nosso site. [...] Graças a um edital do Ministério da Cultura de intercâmbio cultural fizemos ano passado uma turnê pela Europa" (entrevista realizada com Leonardo Campos, músico da Orquestra Voadora, em 08 de março de 2013).

${ }^{29}$ Segundo Maron: "[...] para escolher o local para tocar, temos alguns critérios que não são muito definidos, mas que são basicamente: avaliamos onde a gente pode conseguir tocar, sem que o grupo seja interrompido. Selecionamos um espaço onde a gente pode conseguir tocar e mobilizar uma galera que não necessariamente nos conhece [...]. Em geral, o pessoal que toca na rua tem isso em mente quando procura um espaço para tocar [...]. Já tocamos na Praça Tiradentes e na Praça XV, além de locais menos concorridos e visados pelos grupos de rua, que em geral estão concentrados no Centro da cidade" (entrevista realizada com Miguel Maron, músico dos Siderais, no dia 05 de junho de 2013).
} 
Em suma, talvez com uma participação mais efetiva do poder público ampliando o número de editais de financiamento - dos quais alguns artistas já participam - essas redes de artistas e prosumidores musicais poderiam vislumbrar: não só a possibilidade de uma maior sustentabilidade para este tipo de inciativa, mas também oportunidades para a ampliação da sua atuação. Portanto, algumas áreas da cidade assim poderiam usufruir dos reflexos positivos da "capacidade movente da música" (HERSCHMANN; FERNANDES, 2012a), ou seja, poderiam de alguma maneira se beneficiar mais dos processos de construção e popularização de atrativas "paisagens sonoras" (SCHAFER, 1969) urbanas.

\section{Referências}

ABRAMOVAY, Miriam; GARCIA CASTRO, Mary. (Coords.). Juventudes em comunidades com Unidades de Polícia Pacificadora. Rio de Janeiro: BID, SEASDH/RJ/FLACSO, 2011.

BAKTHIN, Mikhail. Cultura popular na Idade Média e no Renascimento. São Paulo: Hucitec, 2010.

BEI. Guia do Carnaval de Rua do Rio de Janeiro. Rio de Janeiro: BEI Comunicação, 2007.

BORELLI, Silvia H. Cenários juvenis, adultescências, juvenilizações: a propósito de Harry Potter. In: BORELLI, Silvia H.; FREIRE FILHO, João (Orgs). Culturas juvenis no século XXI. São Paulo: EDUC, 2008.

BOURDIEU, Pierre. Questões de sociologia. Rio de Janeiro: Marco Zero, 1983.

. La distinción. Madrid: Taurus, 1991.

CANCLINI, Néstor G. et al. (Orgs.). Jóvenes, culturas urbanas y redes digitales. Madrid: Fundación Telefónica, 2012.

CASTELLS, Manuel. A sociedade em rede. Rio de Janeiro: Paz e Terra, 1999. CASTRO, Ruy. Carnaval de fogo. São Paulo: Cia. das Letras, 2003. 
CAVALCANTI, Maria Laura Viveiros de Castro. Carnaval carioca. Rio de Janeiro: Ed. UFRJ, 1999.

HERSCHMANN, Micael. Indústria da música em transição. São Paulo: Estação das Letras e das Cores, 2010.

. Lapa: cidade da música. Rio de Janeiro: Mauad X, 2007.

; FERNANDES, Cintia S. Potencial movente do espetáculo, da

música e da espacialidade no Rio de Janeiro. In: RIBEIRO, Ana P. G.; FREIRE FILHO, João; HERSCHMANN, Micael. (Orgs.) Entretenimento, felicidade e memória. Rio de Janeiro: Anadarco, 2012a.

Compós, v.15, n. 2, 2012b.

. Nova Orleans não é aqui? In: E-Compós. Brasília:

HOBSBAWM, Eric; RANGER, Terence. A invenção das tradições. Rio de Janeiro: Ed. Paz e Terra, 1984.

JENKINS, Henry. Piratas de textos. Barcelona: Paidós, 2010.

JOÃO DO RIO. Religiões no Rio. Rio de Janeiro: José Olympio Editora, 2006.

. A alma encantadora das ruas. Rio de Janeiro: Cia. de Bolso, 2008.

LATOUR, Bruno. Reensamblar o social. Buenos Aires: Manantial, 2008.

LEGROS, Patrick et al.Sociologia do imaginário. Porto Alegre: Sulinas, 2007.

LEVI, Giovanni e SCHMIDT, Claude (Orgs.).História dos jovens.São Paulo, Cia. das Letras, 1996.

MARGULIS, M. La juventud es más que una palabra. Buenos Aires:

Biblos, 1996.

MARQUES, Márcio. A revitalização do carnaval de rua do Rio de Janeiro.

Revista Jovem Museologia. Rio de Janeiro: Departamento de Museologia da UNIRIO, n. 1, janeiro de 2006.

MATTA, Roberto da. Carnaval, malandros e heróis. Rio de Janeiro: Rocco, 1997.

PIMENTEL, João. Blocos. Rio de Janeiro: RelumeDumará, 2002. 
PRESTES FILHO, Luis Carlos. Cadeia produtiva da economia do carnaval. Rio de Janeiro: E-Papers, 2010.

SCHAFER, R. Murray. The new soundscape.Vancouver, Don Mills, 1969.

VIANNA, Hermano. O mistério do samba. Rio de Janeiro: Jorge Zahar Editor/Editora UFRJ, 1999.

\section{Micael Herschmann}

Formou-se em História pela PUC-RJ, tendo realizado seu Doutorado em Comunicação na UFRJ e estágio pós-doutoral na Universidade Complutense de Madri. É pesquisador 1 do CNPq e professor do Programa de Pós-Graduação em Comunicação da Universidade Federal do Rio de Janeiro. Coordena o Núcleo de Estudos e Projetos em Comunicação (NEPCOM-ECO/UFRJ) e o GP de Comunicação, Música e Entretenimento da INTERCOM. É autor dos seguintes livros integrais: A Indústria da Música em Transição; Lapa, cidade da música; e O funk e hip hop invadem a cena.

Recebido em: 08.08.2013

Aceito em: 09.11.2013 